The University of San Francisco

USF Scholarship: a digital repository @ Gleeson Library |

Geschke Center

2009

\title{
Repositioning the Culture of Power: Advocating for Systemic Change in Public Affairs Education
}

Richard Greggory Johnson

University of San Francisco, rgjohnsoniii@usfca.edu

Cynthia Reyes

Sherwood Smith

Follow this and additional works at: http://repository.usfca.edu/pna

Part of the Education Commons, and the Public Affairs, Public Policy and Public Administration Commons

\section{Recommended Citation}

Richard Greggory Johnson III, Cynthia Reyes \& Sherwood Smith. Repositioning the Culture of Power: Advocating for Systemic Change in Public Affairs Education. JPAE. 2009, 15(1):33-45.

This Article is brought to you for free and open access by the School of Management at USF Scholarship: a digital repository @ Gleeson Library | Geschke Center. It has been accepted for inclusion in Public and Nonprofit Administration by an authorized administrator of USF Scholarship: a digital repository@Gleeson Library | Geschke Center. For more information, please contact repository@usfca.edu. 


\title{
Repositioning the Culture of Power: Advocating for Systemic Change in Public Affairs Education
}

\author{
Richard Greggory Johnson III, \\ Cynthia Reyes \& Sherwood Smith, \\ University of Vermont
}

\begin{abstract}
The present study sets out to characterize and analyze difficulties that typically face faculty of color who teach at Predominantly White Institutions (PWIs). Using personal narratives of junior faculty at a PWI, we explore the themes of shifting identity and marginality for faculty of color as these intersect with the presentation of public selves in university settings. This exploration is consistent with development of the themes of intersectionality and multiplicity in the work of Rivera and Ward in their Spring, 2008 Social Equity and Diversity symposium (2008).

We as authors were initially unsure whether the effort to analyze concerns surrounding multiple identities in a PWI was an act of empowerment, or a strategic response to a work setting where some refused to recognize us as we defined ourselves. Building on this framing question and a review of pertinent literature, we set out to explore how the institutional context shapes our identities as faculty of color. Ultimately, we argue that, in addition to creating inclusive strategies for faculty of color at this level, in order to empower them the PWI must also engage in a critique of the culture of power that still prevails in higher-education institutions.
\end{abstract}

\section{INTRODUCTION}

In July 2006, the Chronicle of Higher Education published an article highlighting a proposal from the University of Michigan regarding the tenure clock (Chronicle of Higher Education, 2006). The University of Michigan's proposal called for junior faculty on the tenure track to receive it after 10 years, rather than after the traditional seven- to eight-year period that is a universal standard in higher education, based on the revised version of the 1940 Statement of Principles on Academic Freedom and Tenure, developed by the American Association of University Professors and the Association of American Colleges (AAUP, 1940). 
Repositioning the Culture of Power:

Advocating for Systemic Change in Public Affairs Education

According to proponents of this proposal, junior faculty today face such complex burdens that they cannot put forth a successful tenure bid without additional time and support, which makes it increasingly difficult to achieve the three components of faculty life needed to reach tenure: research, teaching, and service. There is no doubt that achieving tenure today is immensely different and more challenging than ever before. In fact, few would argue against the observation that a dual and disparate system of responsibilities exists, which often pits work against family and personal life (Wilson, 2005).

The University of Michigan's proposal is certainly not unique. However, still missing from that plan is a focus on faculty of color, and the barriers that prevent them from achieving successful tenure bids or maintaining successful academic careers.

In the following section, we explore research literature on faculty of color, focusing particularly on how it highlights marginalization and isolation as factors that impede the progress of these faculty members while they move through the tenure and promotion process. We see this marginalization as resulting from the work conditions for faculty of color, and how these conditions influence the way they publicly present their personal and professional identities in academia. In this article, we use personal narratives as a way to "self-define" (Collins, 1990), and to draw out our personal experiences in the academy.

Rivera and Ward, in their Spring 2008 JPAE Social Equity and Diversity symposium, suggest that there are multidimensional types of discrimination that may be imposed upon some of the minority faculty who ascribe to multiple identity-markers.

Multidimensional kinds of discrimination may also be experienced by others who combine more than one relevant identity trait, such as a member of a traditionally underrepresented ethnic minority who also has a disability, or a foreignborn faculty member with other prominent identifiers pertaining to race, gender, or religion (p. 15).

\section{LITERATURE REVIEW}

Research on Faculty of Color

Research on faculty of color at Predominately White Institutions (PWIs) continues to grow because of issues that remain critical for this population (Thurman, 2002). Scholars are continuing to tackle questions on why faculty of color leave their respective institutions or do not achieve tenure bids at higher rates than for White faculty. The first reason is a feeling of isolation (Bonner II, 2003; Burden, Harrison \& Hodge, 2005; Turner, 2003). Faculty members of color are often sequestered from one another, making it difficult for them to socialize and mobilize in mutual-support networks with other scholars of color. In some institutions it is common to have just one faculty member of color in a department (Turner, 2000). This isolation often leads to lower productivity, devalued work,

\section{Journal of Public Affairs Education}


Repositioning the Culture of Power:

Advocating for Systemic Change in Public Affairs Education

and denial of tenure/promotion. Fred Bonner II (2003) suggests the following about minority faculty isolation:

Acclimating to the higher-education environment has proven to be a formidable task for many faculty members. Particularly among the ranks of certain subcultures - women, cultural and ethnic minorities, gays and lesbians - their experiences with these environments have been described in the literature as chilly. Therefore, developing necessary survival skills and cultural adaptations to negotiate these frigid academic climates has become the means by which these faculty members learn to survive (p. 80).

Bonner adds that faculty of color also feel isolated because they are not invited to participate in key university-wide committees. Rather, these faculty are often left to sit on committees that solely address diversity or marginalized group issues and concerns, which, while critical with reference to academic and national dialogue, tend to be regarded as having secondary importance and as detracting from traditionally valued scholarship. Additional scrutiny is also placed on these faculty because of the types of scholarship they might pursue (Antonio, 1999; Turner, 2000), especially if they address diversity issues. Turner and Myers (1999) suggest that faculty of color are often criticized for their choice of research topics, particularly for research that exclusively relates to their own communities, which is often seen as peripheral to traditional research agendas. The research foci of faculty of color draw more critique from the larger academic community, even though scholars are encouraged to pursue a research agenda that is of interest to them. However, Smith (2000) suggests that such research will become important for PWIs, as the issue of diversity moves toward center stage for curricula and student affairs

\section{Personal Narratives}

While many authors have written about race, gender, and higher education, there has been little written on the emotional or psychological components of negotiating this territory (Balderrama, Texeina, \& Valdéz, 2004; Williams, 2001). Yet more and more scholars of color are taking risks and exploring this difficult terrain by critically examining their own experiences, and doing so in sanctioned academic journals. While we feel that we put ourselves at risk by sharing the following narratives at a pre-tenure stage, we also feel strongly that to wait and address these issues post-tenure is not a responsible option.

In writing our individual stories, we use the scholarly personal narrative (Nash, 2004) as our framework, because we are deliberately sharing these experiences in order to signify for other scholars of color. We acknowledge that it is difficult to remove the "self" from our research, in any case. In writing about Esperanza, 
Repositioning the Culture of Power:

Advocating for Systemic Change in Public Affairs Education

a Mexican Indian woman featured in the ethnographic work Translated Woman, author Ruth Behar (1993) critically looks at her own identity in a chapter entitled "The Biography in the Shadow." It is in Behar's writing and analysis that we find a model of inspiration and a methodological model for our own self-reflections.

I have supposedly been privileged from the beginning, a Cubanita, another "model minority," a success story, the welcome mat of the American government spread at my feet, in grateful exile from the shackles of communism in the land of freedom. I'm a Cubanita, but in Mexico I'm a gringa because I go to Mexico with gringa privileges, gringa money, gringa credentials, not to mention a gringo husband and a gringo car (Behar, 1993, p. 320).

Behar examined the complexity of her role. On the one hand, her circumstance of being an ethnographer in the academic world gave her a position of power and a privileged stance from which to speak. But, on the other hand, her multiple ethnic identities altered how others perceived her, placing her in a less-than-privileged stance, because they decided which of her selves they would acknowledge. Instead, she would try to speak from that very mix of contradictions "that makes her a halfie, a mestiza, a Norte Americana, almost a gringa, but not quite yet" (p. 339).

In using scholarly personal narratives, we claim that we can draw broader implications. This methodology utilizes the authors' life experiences to generalize to a larger group (Bochner \& Ellis, 2003; Bocher, 2003). Personal narrative writing is a communicative form that can be aptly used by those who "self-identify as 'other,' who have been traditionally underrepresented and disenfranchised in higher education, particularly in professional schools" (Nash, 2004, p. 3). Scholarly personal narrative has also been compared to autoethnography (Crawford, 1996), which enables the scholar to use life experiences as a source of data.

Rather than including all three narratives in their entirety for this article, we analyzed the stories for essential themes. Collectively, our personal narratives may describe some common experiences of other faculty of color. While others have written eloquently about how they resist marginalization, using their writing experiences to counteract their marginalization (Fries-Britt \& Kelly, 2005), or have recommended networking and mentoring strategies for faculty women of color (Turner, 2002), what emerged from our narratives was the need to address more fully the academic climate of the PWI. The literature review addresses how PWIs may support faculty of color, through mentoring opportunities, diversity recruitment strategies, or so-called "cluster-hiring" practices. But what has not radically changed is the PWI itself, and its self-awareness with respect to its culture of power. The culture of power that the authors subscribe to relates to the aspects of power that Lisa Delpit (1995) uses to describe the disconnection between some of the 
Repositioning the Culture of Power:

Advocating for Systemic Change in Public Affairs Education

liberal educational movements and that of non-White, non-middle-class, nonmainstream teachers and communities. Although Delpit used these characteristics to describe the contrasting viewpoints of teaching methodologies between these two groups, we found her ideas on what characterized these aspects of power useful to relating the experiences we encountered in our current working environment. Delpit describes a phenomenon that rests on the idea of working towards a society that is based on individual freedoms and autonomy, but the assumption is that everyone understands the rules or expectations. Furthermore, to make these rules explicit is to limit the freedoms of those who subscribe to this society. Related to our narratives is the aspect of power that Delpit describes as "those with power are frequently least aware of - or least willing to acknowledge - its existence. Those with less power are often more aware of its existence" (1995, p. 26).

What we struggled to do with our narratives was to highlight the parts of our stories that overlapped, as they related to how the climate in our PWI conditioned our ability to be who we were and what we aspired to be. Where our stories overlapped were those moments when who we aspired to be often bumped up against our perception of the lack of power we had in controlling our identities in the workplace.

The three personal narratives describe the experiences of a Filipina-American female and two African-American males. While discussing our experiences one day over tea and coffee, we began to explore the different ways in which our personal identities influenced our public selves, and particularly the ways that we wanted others to perceive us. While we wondered about the general lack of understanding by some of our colleagues toward our personal struggles, we wrestled with the difficult notion of constructing our public selves within our particular - and constraining — work settings. In The Power of Self-Definition, Patricia Hill Collins (1990) described the Afrocentric feminist consciousness as the lens through which Black women could resist controlling systems of race-, gender-, and class-oppression. This was part of a larger idea that female Black writers formed a powerful coalition that offered safe space for the nurturance of African-American women's ideas and experiences. Collins argued that creating self-definitions that reflected this Afrocentric feminist consciousness was essential for personal and professional survival, and "critical for understanding a host of other relationships" (1991, p. 104). Reflecting on Collins' notion of self-definition helped us to articulate our rationale for using personal narratives in the context of our present research.

The following questions then arose:

1) Why is identity important to me?

2) How does my racial/ethnic identity inform my teaching and scholarship?

3) How does the institutional context shape my identity? 
By asking these questions, we try to draw larger implications from them, though we don't claim to generalize for our own communities. We do acknowledge, however, that in asking these same questions, other scholars of color may discover narrative overlap, as well as points of departure, which contribute to the various narrative truths about teaching and researching in a PWI (Nash, 2004). What we strive to do with our personal narratives is critically to examine how our personal stances inform our professional lives, while being consistent with the distinction Brodkey (1987) made between critical narration, and uninterrupted, third-person ethnographic narration. After writing our personal narratives, we analyzed and discussed the central themes that emerged, and together came to realize that our narratives mostly addressed questions about the interrelation of institutional context and identity.

\section{Drawing Upon Personal Experiences}

\section{Shifting Identities}

The concept of shifting identities was addressed in each of our personal narratives. To understand how this notion contributed to our feelings of isolation, we shared specific events in our lives, inside and outside of the academy, that shaped our thinking on multiple and changing identities - admixtures of self-defined and ascribed identity traits (Marable, 2000; Gregory, 2001). One of us, an African-American male, compared the experience to a turning prism that displays changing bands of refracted and reflected color.

The following passages resonated with his sense of changing identity.

When those who have the power to name and to socially construct reality choose not to see you, hear you, whether you are dark-skinned, old, disabled, female, or speak with a different accent or dialect than theirs, when someone with the authority of a teacher, say, describes the world and you are not in it; there is a moment of psychic disequilibrium, as if you looked into a mirror and saw nothing [reflected] (Maher \& Tetreault, 1994, p. 201).

But even this quote has limits for me. Imagine me in Kenya or Tanzania as a Black person. My role is a faculty member for a college semester program in these countries. My skin color ceases to be the defining public characteristic. But because of colonialism there is still a difference in how I am treated. Because of my class status, which is that of the wealthy American, I have privileges. I have a rental car, I am paid in U.S. dollars, and I get a living allowance to cover food, lodging, and travel. Gold-rimmed glasses for my near-sightedness; a minor disability raises my status because of its appearance and its status. It is not only race but my nationality that is most likely to be the topic of discussion as a U.S. citizen. My identity shifts with time, place, and who I currently exist to be (Adams, Bell, \& Griffin, 1997, pp. 282-283). 
Repositioning the Culture of Power:

Advocating for Systemic Change in Public Affairs Education

Having traditionally identified himself as a social-justice scholar first, and as a gay African-American individual second — in the classroom as well as with colleagues and administrators - one of us began to rethink how his students positioned him and continued to stereotype him because of his race and perceived sexual orientation, instead of judging him on his pedagogy. A disgruntled student who had not been successful in a race and culture class accused the faculty member of sexual harassment. This particular experience compelled the faculty member to think that he had little power over the way he wanted to present himself in public.

Due to stereotypes of African-American men in movies and gangster rap, the student thought it would be simple enough to accuse me of sexual harassment charges. I don't make it a point of sharing my personal life with my students. Therefore, none of them knew that I was gay. But more importantly, the student did not think that I could be gay because of my being Black and non-effeminate; the power of stereotypes or nonstereotypes can be a powerful drug. The student transferred to another university after admitting that her story was fabricated. However, the scars of that experience will be with me for years to come. I still wonder how many scholars of color have fallen in their careers because of such allegations - especially Black men (R. Johnson, personal communication, November 6, 2002).

Issues of identity also manifested themselves for the Filipina-American female faculty member as she explored what it meant to engage in research with a research participant who was also of color. The notion of doing research with others of color raised the issue of hierarchy of privilege. As a researcher, she was perplexed about how to reconcile the issue of power inequity between herself and the other individual of color. She recalled the words of anthropologist Ruth Behar, who noted, "Here is the paradox of doing ethnographic work — it is a process by which each of us confronts our respective inability to comprehend the experience of others even as we recognize the absolute necessity of continuing the effort to do so" (1993, p. 271).

In exploring identity within the perceived insider's perspective, I advocate for exploring multiple social borders and the interconnections for hybrid identities. Regarding the teaching and research work that I do, I continue to acknowledge how research evokes, in Behar's words, "the grief of diaspora" (Behar, p. 21). As I was confronted about my perceived connections to the identity of my Latina participant, it acted as a catalyst for exploring the multiple lens - that of university teacher, Filipina American of postcolonial heritage, and child of 
Repositioning the Culture of Power:

Advocating for Systemic Change in Public Affairs Education

immigrant parents — adding a set of complex layers to the observations, inquiries, and interpretive writing that I engaged in (C. Reyes, personal communication, October 23, 2006).

While the authors were able to reflect on the intersection of their personal narratives and share complex experiences of identity, one constant remained unchanged — the daily interactions in a too-often adverse work setting.

\section{Marginalization}

There is extensive research on the marginalization of faculty of color, as well as on the various ways that PWIs strive to address the isolation that faculty of color generally feel in the work setting. While these efforts center on practices such as recruitment, hiring, mentoring, and retention of faculty, they seldom acknowledge, much less address, larger problems of the workplace climate. In recounting an earlier struggle with her identity as an adolescent Asian female, the Filipina American female faculty member describes a feeling of isolation that in some ways still resonates for her as an assistant professor at a PWI.

In high school, I was the only Filipina American, and I seemed to fit in with students of different ethnicities; European Whites, African Americans, and Eastern Europeans. There were even fewer Latinos, only two that I remembered in my entire high school ... My graduating class was small and formed tight-knit multicultural relationships. Black and White students teased each other jokingly about color. Some of the seemingly derogatory wordplay included Black friends teasing White friends about their pallid complexion and their inheritance of bad dancing, while White friends teased their Black counterparts about their Afro hair; this was still in the '70s. Sometimes they teased themselves, further exaggerating stereotypes. I perceived this discourse as a way for my friends to counteract stereotypes and resist them. Yet, I never gave myself liberty to do the same. While I felt relieved that the racial talk never focused on my own appearance or ethnicity, I realized later on, as negative and derogatory as these stereotypes were, exposure to them announced the existence of racial tension even in our little, multicultural school. These stereotypes and ribbing despite all its inappropriate implications acknowledged the presence of race in the outside world, as well as gave voice to my Black and White friends who indulged in this discourse, in a way, to acknowledge their presence. Perhaps, it even acknowledged their need to work out their own identities through these joking sessions. Always on the periphery, there was never a need to single out the only Filipina American since I was the only one. How safe I felt, how relieved I was to not receive attention. Yet I was living in my own world. By not 
Repositioning the Culture of Power:

Advocating for Systemic Change in Public Affairs Education

participating I didn't belong to either group. I was the spectator looking on, observing, and laughing along with the rest (C. Reyes, personal communication, September 2, 2007).

Reflecting on his current position, the African-American gay faculty member described his experiences of teaching in different fields that included educational leadership, management, and counseling roles and duties. He sought to integrate his social-justice ideology across different disciplines, in spite of the resistance that he sometimes met from his students.

For example, human resources management is one of my subfields and I write on social justice issues within that area. But my students generally don't understand why I raise the issue of diversity in class discussions and the readings. This lack of understanding undermines the very crux of who I am as an African-American, gay academic. Such resistance to diversity instruction is also reflected in my student evaluations as well. Students have written on my past teaching evaluations that they believed that I used the classroom for my own personal agenda in order to advance the notion of diversity. I am not surprised by these comments at all. Coleman (1998) found that faculty of color received significantly lower class evaluations than White faculty. And minority women tended to receive even lower evaluations than minority men. Indeed, Coleman found that there was a direct correlation between what faculty of color taught and the evaluations they received (R. Johnson, personal communication, May 14, 2004).

These faculty members shared the experience of not being understood by their students. Working in isolation often exacerbated their sense of marginalization. For one of the African-American male faculty members, a feeling of isolation was often associated with the persistence of racial stereotypes. In the following, he describes how an off-hand compliment still seems denigrating.

Years later, I completed a post-doctoral fellowship. My greatgrandmother and my parents would tell me that I was a success if they were still alive. I am the second in three generations of my family to get a college degree and the first to get a doctorate. Yet each day I would walk home from campus at about five in the afternoon. The streets were clogged with cars as I crossed Main Street. But I could still be assured of hearing the car doors locking as I walked past the White drivers stuck in rush-hour traffic.

They say that change is inevitable but sometimes I wonder. Some things seem not to have changed significantly from my youth. I grew 
Repositioning the Culture of Power:

Advocating for Systemic Change in Public Affairs Education

up in a lower-middle-class Black neighborhood in New Jersey; the "stereotypical" African-American family with a single mother living with her parents. It was over 40 years ago when my White classmates tried to off-handedly tell me I was not like the other Blacks from the fourth ward (a poor Black section) of my town in New Jersey. Years later as a Black faculty member at a predominantly White university I get a slightly different compliment about my pedagogical skills and style, "You are not like the 'other'; you're not angry and you do not have an agenda you are pushing. I can really listen to you" (S. Smith, personal communication, July 10, 2005).

While it is clear that the misguided compliment relates to the stereotyped ("angry") Black man, it also points to a more disturbing, assimilationist stereotype. The White faculty could only really see, hear, and understand his or her facultyof-color counterpart if he or she was able to identify with - see him or herself in the words, actions, and behaviors of - the "other." And just as there needs to be identification — identity — across racial, ethnic, and gender lines, there also needs to be a recognition of and a break with the PWI's own situated, taken-forgranted culture of power.

\section{Conclusion}

In this article, we seek to examine the common challenges that faculty of color teaching at Predominately White Institutions face. Some of the common themes we discovered in our personal narratives were shifting identities and marginalization. These themes also characterized the multiple identity-markers that describe some junior faculty, as suggested in the Spring 2008 Social Equity and Diversity JPAE symposium by Rivera and Ward (pp. 9-20). The scholarly personal narrative became a thought-provoking methodology for exploring narrative overlap.

One of the African-American faculty members described in his narrative a scenario in which he was mistakenly identified as someone else. Afterwards, he questioned the original stance from which others were trying to ascribe identity traits to him.

It is not just the individual actions that are created, but rather the institutional actions that have been nurtured by culture and context. The context has a defined space for me and the role of faculty is in conflict with the cultural constructed ideas about race in the U.S. (Banks, 1995). For example, on arrival at a workshop on intercultural communication, a lead participant asked me to fill the empty container with more soda for the break. "Oh, I am a faculty member here at the university like you," I tell my colleague, and she had the good grace to blush. But the temporary embarrassment moved to the usual perfectly logical explanation. "I 
Repositioning the Culture of Power:

Advocating for Systemic Change in Public Affairs Education

thought you were a waiter because you are wearing a vest. "Ah, it all makes sense, it is my vest not my race that has confused her. At that time our university catering service had no African Americans on staff and I had never seen any of them in a rainbow-striped vest with hanging teardrop brass buttons. I fit her construction of a waiter in that space (Berger \& Luckman, 1967) and her explanation of the vest never addressed the possibility that race could be the issue (Yamato, 1988) (S. Smith, personal communication, October 12, 2008).

We argue that this event represents more than a simple error of judgment; it represents behaviors, a way of being, that are firmly rooted in the institution by many of its affiliates. They emerge in the way that faculty of color are identified, misidentified, or simply not identified, overlooked, or made subject to inept value judgments. The PWI may provide support and inclusion strategies for its faculty of color, but that typically does not go far enough to change biased perceptions.

We acknowledge the leadership of our own institution and the promising steps it has taken to more profoundly address issues of diversity. Some public affairs faculty have initiated small self-study groups that engage provocative readings and discussions on the intersections of power, privilege and race. Given the initiative on the part of some of our White colleagues, we are confident about starting to look at the culture of power that exists in our own institution. Beyond these initiatives, we realize that this work needs to extend beyond our own college to the entire university, to reconnect the diversity-oriented work that exists in other departments and colleges. By doing this critical work, our hope is to distribute power equitably to all faculty members teaching at our PWI.

By exploring our own individual narratives, we seek to highlight the complexity of the interrelationship of identity and institutional context. As each narrative demonstrates, identity, according to one of the authors, is the sum of the multiple prisms that we allow ourselves to view. While we acknowledge that our experiences are ours, we do believe that these experiences may resonate with other public affairs faculty of color who also teach at PWIs. Identity is important because of how White students, peers, or administrators may perceive, define, and consequently treat faculty of color. But, identity is even more important for how faculty of color choose to identify themselves at a PWI without fearing reprisal or isolation.

\section{REFERENCES}

Adams, M., Bell, L.A., \& Griffin, P. (1997). Teaching for diversity and social justice: A source book on racism, heterosexism, sexism, ableism and classism. (pp. 282-283). New York: Routledge.

American Association of University Professors and the Association of American Colleges. (1940).

Statement of Principles on Academic Freedon and Tenure. Retrieved December 2007. http://www.aaup. 
Repositioning the Culture of Power:

Advocating for Systemic Change in Public Affairs Education

org/AAUP/pubsres/policydocs/contents/1940statement.htm.

Antonio, A.L. (1999). Faculty of color and scholarship transformed: New arguments for diversifying faculty. Diversity Digest. 3(2), 6-7.

Balderrama, M., Texeira, M., \& Valdéz, E. (2004). Una lucha de fronteras (A struggle of borders): Women of color in the academy. Race, Gender, and Class: An interdisciplinary and multicultural journal. 11(4), 135-154.

Banks, J. (1995). The historical reconstruction of knowledge about race. Educational Researcher, 24, $15-22$.

Behar, R. (1993). Translated Woman: Crossing the Border with Esperanza's Story. Boston: Beacon Press.

Berger, P. \& Luckman, T. (1967). The social construction of reality: A treatise in the sociology of knowledge. New York: Anchor Books.

Bonner II, F.A. (2006). The temple of my unfamiliar. In C. Stanley (Ed.), Faculty of color teaching in Predominantly White institutions (80-99). San Francisco: Jossey-Bass.

Brodkey, L. (1987). Writing critical ethnographic narratives. Anthropology and Educational Quarterly, 18(2), 67-76.

Burden Jr., J.W.; Harrison Jr., L.; Hodge, S.R. (2005). Perceptions of African American faculty in kinesiology-based programs at predominantly White institutions of higher education. Research Quarterly for Exercise and Sport, 76(2), 224-237.

Coleman, T. (1998). To be young, gifted and a Black female professor. APA Newsletter [On-line], 98 (1). Retrieved December, 2008, from http://www.apaonline.org.

Collins, P. (1990). Black Feminist Thought: Knowledge, Consciousness, and the Politics of Empowerment. New York: Routledge.

Crawford, L. (1996). Personal ethnography. Communication Monographs, 63, 158-170.

Delpit, L. (1995). Other people's children: Cultural conflict in the classroom. New York: The New Press.

Fries-Britt, S. \& Kelly, B. (2004). Retaining each other: Narratives of two African American women in the academy. The Urban Review, 37(3), 221-242.

Gregory, S. (2001). Black faculty women in the academy: History, status and future. Journal of Negro Education, 70(3), 124-138.

Maher, F. \& Tetreault, M.K. (1994). The Feminist Classroom: Dynamics of gender, race, and privilege. Rowman and Littlefield: Lanham, MD.

Marable, M. (2000). Dispatches from the Ebony Tower: Intellectuals Confront the African American Experience. New York: Columbia University Press.

Nash, R. (2004). Liberating scholarly writing: The power of personal narrative. New York: Teachers College Press.

Reyes, C. (in press). Disturbing the waters: Using relational knowledge to explore methodology. In The Journal of Educational Studies, 22(3-4).

Rivera, M. \& Ward, J.D. (2008). Employment equity and institutional commitments to diversity: Disciplinary perspectives from public administration and public affairs education. Journal of Public Affairs Education. 14(1), 9-20.

Smith, B. (1983). Home Girls: A Black feminist anthology. New York: Dover Publications, Inc.

Tatum, B. D. (2003). Why Are All The Black Kids Sitting Together in the Cafeteria? New York: Basic Books.

Thurman, T. (2002). Are we there yet? Retaining faculty of color. Black Issues in Higher Education, 19(3), 58.

Turner, C. \& Myers Jr., S. (1999). Faculty of color in academe: Bittersweet success. Boston: Allyn \& Bacon.

Williams, C. (2001). The angry Black woman scholar. NSWA Journal, 13(2), 87-97.

Wilson, R. (July, 2006). Off the clock. The Chronicle of Higher Education, 52(46), A48.

Wilson, R. (February, 2005). Report calls for a more flexible tenure process. The Chronicle of Higher Education, 51(25), A13.

Yamato, J. (1988). Racism: Something about the subject makes it hard to name. In Cochran, J.W., Langston, D. \& Woodward C. (Eds.). Changing Our Power: An Introduction to Women's Studies, 3-6. Dubuque, Iowa: Kendall/Hunt Publishing Co. 
Repositioning the Culture of Power:

Advocating for Systemic Change in Public Affairs Education

Richard Greggory Johnson III is an assistant professor of Leadership and Policy Studies at the University of Vermont (UVM). His recent books include Resilience: Queer Professors from the working class (with Ken Oldfield, SUNY, 2008) and A 21st century approach to teaching social justice: Educating for both advocacy and action (Peter Lang, 2009). Johnson's articles have appeared in the International Journal of Public Administration and The American Review of Public Administration. He obtained his doctorate in Public Policy and Administration from Golden Gate University and master's degrees from Georgetown University and DePaul University.

Cynthia Reyes is an assistant professor from the University of Vermont who teaches literacy education in the middle-level and secondary-education programs. Her research areas include the intersection of language, literacy, and identity; policy issues in literacy; and social justice. She holds her doctorate from the University of Illinois at Chicago.

Sherwood Smith has a faculty appointment in Integrated Professional Studies, and administrative responsibilities as Director of the Center for Cultural Pluralism at the University of Vermont. These joint positions involve conducting faculty and staff workshops, teaching graduate and undergraduate multicultural and human-development/policy courses, and researching issues of intercultural communication, cultural identity-development and public affairs education. $\mathrm{He}$ holds a doctorate from Ball State University. 